\title{
Theoretical Research on Practical Application of Professional Auditing of Information System
}

\author{
Mu Yong, Zhang Yansheng, Zhao Ying and Niu Jinjing \\ Beijing Information Resource Management Center, Beijing 100101, China \\ muy@bjeit.gov.cn, zhangyansheng@huadi.com.cn
}

\begin{abstract}
There are some common problems of information systems. For example: The system workflows don't not match actual business process. The data are not standard. System don't meet the technical document, ect. In the paper, we put forward the concept of "Information System Professional Auditing", then we define its connotation and extension. We point out its objectives, targets, contents, basis, methods, tools, strategies, organization, process, result and effect. The theory has been practiced on 28 information systems in a government department, and has got good results.

Index Terms - Information System Professional Auditing; Research; Practice.
\end{abstract}

\section{Introduction}

After years of informatization construction, the departments and enterprises built a large number of information systems, which played an important role in enterprise management and public services, since these systems were mostly built and maintained in different periods by different manufacturers, as years of continuous upgrading, many problems reflect, for e.g. the system and technical document are " two layers ", systems do not match the actual business process, functions and interfaces are perplexing and difficult to control, data standardization degree is low, data security risks has gone up and so on, which bring up difficulties to system transformation and interoperation in future.

In order to solve these problems, the developed countries put forward the concept of "IT audit "in Nineteen Sixties, namely "the activities of inspection and evaluation of integrated information system objectively by independent IT auditor, and put forward the problems and suggestions to the supreme leader." Starting from Nineteen Nineties, domestic experts and scholars tried to bring the concept of "IT auditing" into China, but in the development process, theories and methods from abroad did not adapt to the actual situation in our country, unable to effectively guide the practice of IT auditing in China. At present, domestic IT auditing mainly refers to two aspects_- financial auditing and information security auditing. However, the professional information system auditing which oriented to the technical documents, business process, data, function, interface and other aspects is still in the blank.

In this context, in accordance with the characteristics of egovernment information system, we carried out cutting and extensions on "IT audit", and formed a new concept to meet the requirement of present development stage —— Information System Professional Auditing ("ISPA" for short).

\section{Concept And content of ISPA}

A. Concept and position

Information System Professional Auditing refers to "An activities of inspecting and evaluating the information system according to national and international standards from some aspects, such as technical documents, business process, data, functions, interfaces; Supplementing and improving technical documents, correcting business process, making clear of the data relationships and operation rules, and putting forward the problems and professional advice to the supreme leader."'The auditing report will be used as an important basis of system integration, data migration, information sharing, system operation and maintenance.

As to the position of ISPA, we see ISPA as an inheritance and extension of "IT Audit". At present, the domestic IT Audit includes two aspects: financial auditing and information security auditing, implemented by the financial audit department and security evaluation department. ISPA inherits "hardware and software test" from "IT audit", while put more emphasis on localization — supplementing technical document, revising the business process, system function, interface, and data relationship.

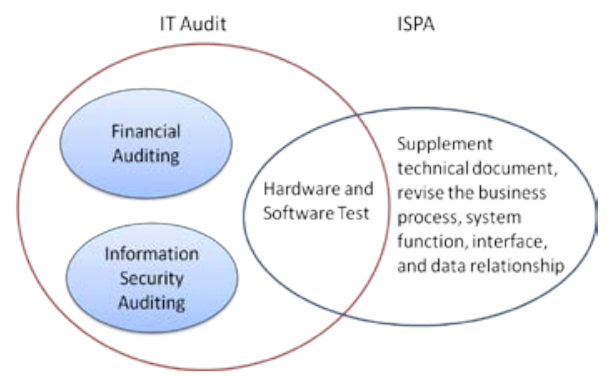

Fig. 1 Relationship between IT audit and ISPA

\section{B. Objectives, targets and contents}

The goals of ISPA embodies in: 1) find the problem of technical documents, such as contents incomplete, functions inconsistent, data incorrect, and supplement the technical documentation; 2) clear and correct the problem of business process, system functions, interfaces, data relationship and operation rules; 3) check the system operation efficiency and effectiveness; 4) give suggestions to system operating conditions and performance.

The target of ISPA can be a single system or a set of systems. The following three kinds of systems should be given 
priority: one is systems that undertaking relatively important business; two is systems that have many problems in developing process; three is systems to upgrade or integrate. ISPA mainly inspects and evaluates: 1) whether the technical document is compliance, complete, consistent and available; 2) whether the business process and responsibility meet the specification or have hidden dangers; 3) whether the data is standard, usable and unified; 4) whether the function is matching with technical document and effective; 5) whether the interface is normative, and exactly defined; 6) whether the performance of hardware and the overall system is obvious.

\section{Basis, methods and tools}

ISPA should be complied with relevant national or municipal standards and rules, such as 《GB8567-2006 specification for computer software documentation 》, 《 GB19488-2004 data element part 1: design and management regulations for electronic government 》, 《GB19487-2004 business process design method general specification for electronic government $\rangle$ and so on.

A variety of methods can be used to implement ISPA. For e.g., audit the consistent of documentation and system by developers investigation and inquiry; audit the compliance of business process and post setting by " integrated business model "; audit data specification and availability by data extraction and analysis; audit weather interfaces are reasonable and orderly through monitoring and online package transmission; audit the system equipment operating efficiency and energy consumption by CPU ratio and other indicators.

All kinds of computer aided tools can be used to improve the quality and efficiency of ISPA. Such as the professional business modeling tool, data elements analysis tool, or general database development tools (PL/SQL), database design tools (PowerDesginer), as well as some open source tools, such as interface analysis tools.

\section{Organizations}

ISPA involves all aspects of an information system, so it needs tripartite confrontation between professional auditing institutions, unit under auditing and system developers.

Professional audit institution should have complete professional technical ability and mature work pattern of ISPA, and the companies which have engaged in system(under auditing) development, system supervision or system advisory could not be involved in ISPA; unit under auditing need to designated a specialized personnel as a director, and organize meetings for system demonstration; system developers need to specify the project manager or technical director to coordinate with the auditing institutions, make system demonstration, complement technical documents, and give a clear answer to each question from audit institutions.

\section{E. Implementary strategies}

According to system's complexity, size and developers, there are three kinds of implementary strategies of ISPA: 1)“simple auditing process", applies to systems which are small size, well documented, in good use and the system developers work closely with the audit institution, in this case, we should only rely on technical documents and developers to implement auditing ; 2)“general auditing process”, suitable for the systems with higher complexity, large scale, data defects, in this case, except by means of documents and developers, we also need to set up test environment to implement auditing; 3) "complex auditing process", for systems which are complex, large, bad documented, and system developers do not coordinate well, then we should use professional tools to do reverse modeling analysis to implement auditing.

\section{F. Process}

ISPA process is mainly divided into four stages: preparation, normative auditing, substantial auditing and drawing up report.

For preparation, audit institutions collect 13 kinds of technical documents, design audit indexes in accordance with "GB/T 8567-2006 ", issue a set of investigation tables to the system develops, including function table, interface table and report table, to get a bird view of the systems.

In the stage of normative auditing, audit institutions evaluate the 13 kinds of technology documents one by one according to the audit indexes, form the " index table "; based on which the final conclusion are given from document integrity, consistency and usability.

In the stage of substantial auditing, first ,the developers would make system demonstration, audit institutions check on business flow, data flow, functions, interface and other parts of the system, communicate discovered problems with developers; second, verify the consistency between technical documents and business system, including consistency of operating functions, statistics statements, system interface and data; third, developers make large-scale supplement to the technical documents on requirements.

Supplementary documents are the important basis for audit reports. Supplementary documents include five aspects: one is the business model, including organization model, job execution model, business collaboration model and data relationship model. The core is business collaboration model, namely "cooperative relationship between posts". The organization, data resources and responsibilities can be gathered and showed based on business collaboration model, and form an "integrated business model”.

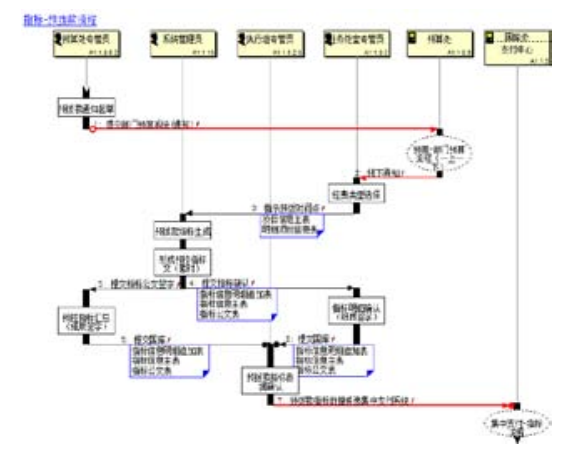

Fig. 2 Example of business collaboration model 


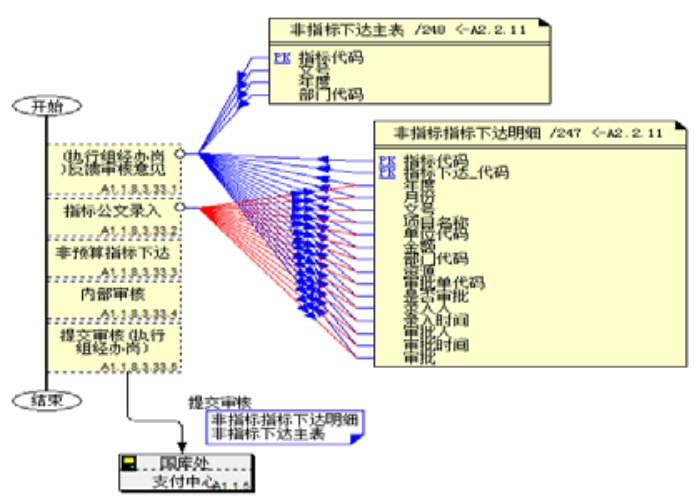

Fig. 3 Example of job execution model

Second type of supplementary document is functional page's interaction design, including the migration diagram and description of functional pages, data flow table and data dictionary.

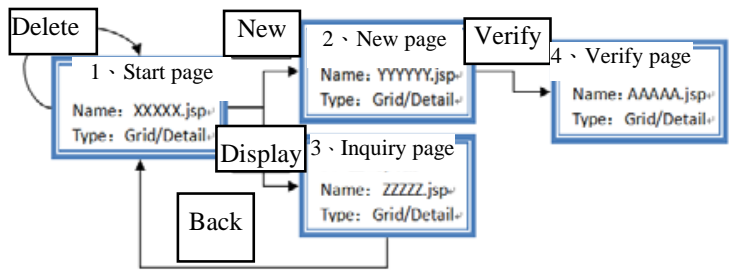

Fig. 4 Example of migration diagram of functional pages

Third type of supplementary document is the report design, including the report page design, data flow and statistics calculation of key data.

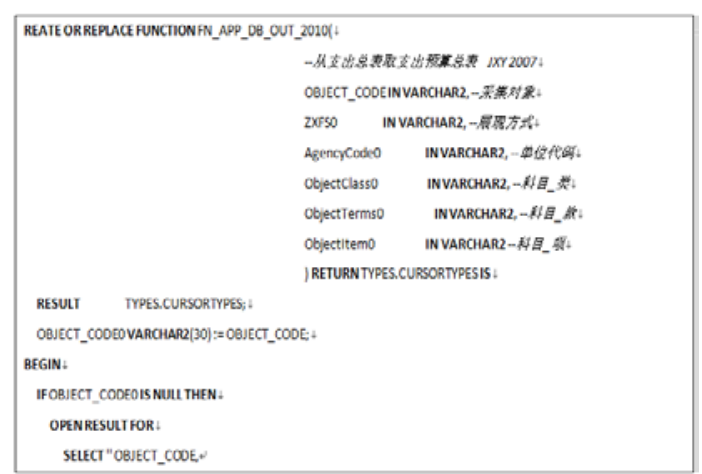

Fig. 5 Example of PL/SQL of report page

Fourth type of supplementary document is the system interface, including the whole structure of system interfaces, and business description of each interface , interface type, message format and exchange data table.

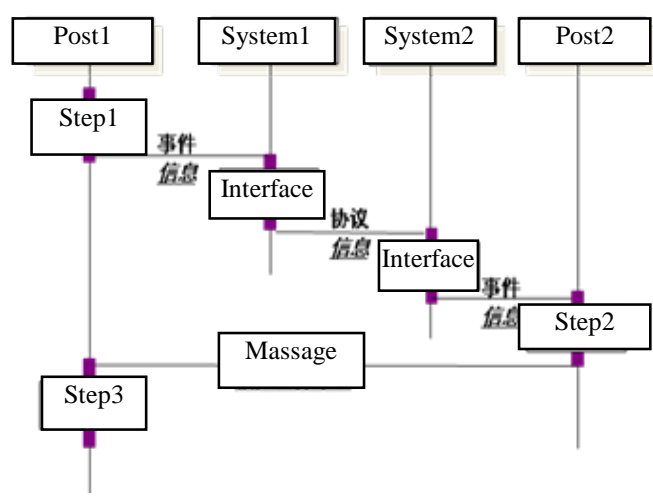

Fig. 6 Example of business description of interface

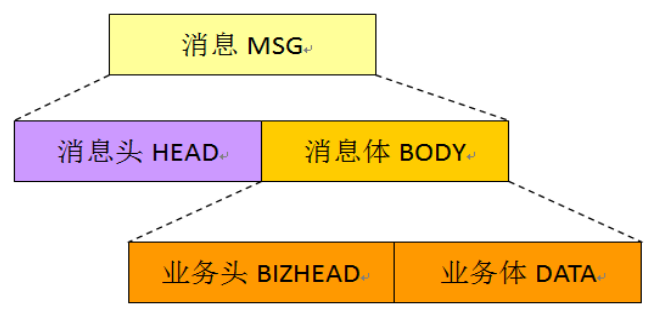

Fig. 7 Example of message format

Fifth types of supplementary document are Chinese semantic of database fields.

Finally, draw up the auditing reports based on the audit process.

\section{G. Reports}

The auditing reports include main report and special reports. The main report introduces ISPA's background and target, content and process, results, problems and suggestions, and the overall conclusion; the special report gives conclusion to each business system.

In addition to the main report and special reports, there are also four accessories, which are the core and essence of audit reports. 1)" report on data rules ", the report gives a detailed description of the data rules of the system, including business model, data rules of interactive page operation 、interface report, which are confirmed by the auditing team; 2)" report on business entities ", describes all data tables with Chinese semantics, and data dictionary; 3)" report on conformance of system ", describes the current situation of system functions, interfaces, data ,and whether they are consistence with documents;4)" document auditing table ", describes the conclusion and index in system normative auditing.

\section{H. Role of ISPA}

ISPA means a "diagnostic "and "improved" process to an information system. On the one hand, It can discover the problems and irregularities in technical document, business process, responsibilities, data quality, system function, system interface, operation and maintenance management; on the other hand, aiming at the problems found, it supplements technical document, revises business model, system function, interface data, etc., which effectively improve the usability of 
technical documents, protect the historical data resources, reduce the excessive dependence on system developers, and provide a foundation for system upgrading, data migration and information exchange in the future.

\section{Typical case of ISPA}

\section{A. Background and process}

A bureau of Beijing has constructed more than 80 information systems, which played an important role in business, however, since these systems were built on different times by different manufacturers, the systems' architecture, data format, technical standards were not unified, which were difficult to meet the future needs for information sharing and business collaboration. In order to effectively control "chaos "of systems, the agency hired professional audit institutions to implement ISPA to 28 core business system, which lasted 1 year.

According to the importance of systems, the 28 systems were divided into two periods, five batches for ISPA. 27 systems applied to “general auditing process”, only 1 system's technical documents were completely deficiency, and developer could not be contacted, so it executed "complex auditing process”. The bureau sent 2 special personnel to guide the audit, 8 system developers designated project manager or technical director, totally 13 people to corporate with the work.

\section{B. Results and effects}

( a ) By implementing ISPA to the 28 systems, we found out many problems in technical document, business process, responsibilities, data quality, function interface, operation management and so on: document missing rate reached $46.7 \%$, document standard rate was 38.8\%, 70.1\% documents were inconsistent with system, the usability of document was just 5\%;142 business process (described in system requirements document )were not correspond to the actual work flows, 4 hidden safety problems were found in the personal responsibility; vacant table rate reached 38\%, Chinese semantic vacancy rate reached $90 \%$, semantic repetition of basic data was high; waste function rate was $17.4 \%$, the interfaces were reticular structured, perplexing, and most of them were in hard coded, difficult to control; system technical document management was not standard, and lack of version control; system development, operation and maintenance were not separated. The bureau excessively depended on developers.

( b ) According to these problems, 4852 pages of technical document had been supplemented, including 142 business collaboration flows, 1116 job execution process, 865 interactive interface design, 113 interface relationship design, 617query and report, 1521 business entity forms and 27972items. This work made the availability of technical documents increase from 5\% to more than $90 \%$.

( c ) According to the business process analysis and modeling, the main business lines and business classification were constructed, "three-levels" business structure of "1 core business lines -25 business -147 process" were built; based on business cooperation model, business panorama of the bureau was generated, which played an important guiding role for information construction of the bureau.

( d ) Based on business line and classification, 8 kinds of shared core data was extracted, shared data framework was preliminary designed. This work enhanced data standardization, planed data as a whole, trengthened information resources management.

( e ) A set of index for ISPA was designed based on "GB/T8567-2006 specification for computer software documentation ", in the meanwhile, an management system of ISPA was built, which provided a way to manage and display the whole results of ISPA, by which realized the visualized management of technique documents and relevant information resources.

( $\mathrm{f}$ ) Based on the results of the audit, some consulting service, such as information construction standards consulting, business process management consulting, basic data coding standard consulting, data migration consultation, system integration project consulting, enterprise architecture design consulting were provided by audit institution, which strongly supported system development, integration and data migration.

\section{References}

[1] Hu Kejin, et al, "IT audit (Second Edition)". Publishing House of electronics industry, 2004.11

[2] Zhuang Ming, Wu Qinhong, Li Jun, "The contents and methods of information system audit.” China Economy Publishing House, 2008.8

[3] ISACA,IT Standards, Guidelines, and Tools and Techniques for Audit and Assurance and Control Professionals,2010.8

[4] ISACA,COBIT 5: A Business Framework for the Governance and Management of Enterprise IT

[5] ISACA,COBIT 4.1: The globally accepted IT governance framework

[6] LIU Ruzhuo.IT Audit in China. Cengage Learning, 2009.8

[7] ISACA,Case study on using COBIT 5 for strategy implementation, 2013.2

[8] China Certified Public Accountants Auditing Standards No. 1211

[9] China Certified Public Accountants Auditing Standards No. 1313

[10] Independent Auditing Specific Standard No. 20 - computer information system environment 